\title{
Penetapan Kadar Fenolik Total Ekstrak Kacang Panjang (Vigna unguiculata) dengan Metode Spektrofotometri UV-Visible
}

\author{
Lalu Aang Robby Dewantara ${ }^{a, 1^{*}}$, Agus Dwi Ananto ${ }^{a, 2}$, Yayuk Andayani a,3 \\ aProgram Studi Farmasi, Fakultas Kedokteran, Universitas Mataram, J1. Majapahit No.62, Dasan Agung Baru, Mataram, 83I26 \\ 1.robbydewantara57@gmail.com*; ${ }^{2}$ agus_da@unram.ac.id; ${ }^{3}$ yayukmtr@gmail.com \\ *korespondensi penulis
}

\begin{tabular}{|c|c|}
\hline INFO ARTIKEL & ABSTRAK \\
\hline $\begin{array}{l}\text { Diterima : } \\
\text { 28-I2-2020 } \\
\text { Revisi : } \\
\text { O5-0I-202I } \\
\text { Disetujui : } \\
\text { O6-OI-202I }\end{array}$ & $\begin{array}{l}\text { Kacang panjang (Vigna unguiculata) merupakan salah satu tanaman yang } \\
\text { berpotensi sebagai antioksidan karena mengandung metabolit sekunder } \\
\text { hampir di seluruh bagian tanamannya, seperti pada daging buahnya. Penelitian } \\
\text { ini bertujuan untuk menentukan kadar fenolik total ekstrak etanol dan ekstrak } \\
\text { air daging buah kacang panjang dengan metode spektrofotometri UV-Visible. } \\
\text { Sampel daging buah kacang panjang dimaserasi menggunakan dua pelarut } \\
\text { berbeda, yaitu pelarut etanol } 96 \% \text { dan pelarut air. Analisis kadar fenolik total }\end{array}$ \\
\hline $\begin{array}{l}\text { Kata kunci: } \\
\text { Kacang panjang (Vigna } \\
\text { unguiculata); } \\
\text { Spektrofotometri } U V \text { - } \\
\text { Visible; } \\
\text { Kadar fenolik total. }\end{array}$ & $\begin{array}{l}\text { dilakukan dengan metode spektrofotometri } U V \text {-Visible. Kadar fenolik total } \\
\text { dinyatakan dalam gallic acid equivalent (GAE). Hasil analisis menunjukkan } \\
\text { bahwa kadar fenolik total ekstrak etanol kacang panjang sebesar } 40,4173 \pm \\
4.2303 \mathrm{mg} \text { GAE/g dan kadar fenolik total ekstrak air kacang panjang sebesar } \\
60.6062 \pm 2,8533 \mathrm{mg} \text { GAE/g. Ekstrak etanol dan ekstrak air dari daging } \\
\text { buah kacang panjang berpotensi sebagai antioksidan dilihat dari parameter } \\
\text { kadar fenolik totalnya. Berdasarkan hasil penelitian, diperoleh bahwa kadar } \\
\text { fenolik total ekstrak air lebih tinggi dibandingkan ekstrak etanol daging buah } \\
\text { kacang panjang. }\end{array}$ \\
\hline
\end{tabular}

Key word:

Cowpea (Vigna unguiculata);

Spectrophotometric UV-

Visible;

Total phenolic content.

\section{ABSTRACT}

Cowpea (Vigna unguiculata) is one of the vegetables that have antioxidant potential due to it contains some secondary metabolites that scattered on every part of the Cowpea, such as the pod coat. The aimed of this study was to determine total phenolic content of Cowpea pod coat ethanolic extract and aqueous extract using UV-Vis spectrophotometry method. Cowpea pod coats were macerated using two different solvents, ethanol $96 \%$, and aqueous. Total phenolic content was showed as gallic acid equivalent (GAE). The analysis results showed that total phenolic content of ethanol extract of cowpea was $40,41732 \pm 4.2303 \mathrm{mg} \mathrm{GAE} / \mathrm{g}$ and total phenolic content of aqueous extract of cowpea was $60.6062 \pm 2,8533 \mathrm{mg}$ GAE/g. The ethanolic extract and aqueous extract of cowpea pod coat have antioxidant potential in terms of total phenolic content parameter. Based on the research, the total phenolic content of cowpea pod aqueous extract higher than cowpea pod coat ethanolic extract.

This is an open access article under the CC-BY-SA license.

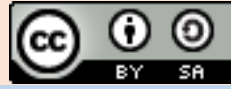

\section{Pendahuluan}

Kacang panjang (Vigna unguiculata) merupakan tanaman dari keluarga Fabaceae yang sering dikonsumsi oleh masyarakat Indonesia sebagai sayuran (Rahayu, 2013). Kacang panjang merupakan tanaman menahun yang tumbuh merambat (Ibrahim, dkk., 2017). Kacang panjang mudah didapat, memiliki harga yang ekonomis dan mudah dibudidayakan sehingga banyak dijumpai serta ketersediaannya cukup banyak di Indonesia (Hermawan, 2015). Menurut data Badan Pusat Statistik pada tahun 2017, produksi kacang panjang mencapai 381.189 ton di Indonesia dan mencapai 4.918 ton di Nusa Tenggara Barat. Selain menjadi sayuran yang enak untuk dimakan, kacang panjang juga memiliki banyak manfaat kesehatan. Kacang panjang mengandung beberapa metabolit sekunder 
seperti glikosida, alkaloid, flavonoid, tannin, polifenol, dan saponin. Pemanfaatan kacang panjang di bidang kesehatan sangat banyak, antara lain sebagai astringen, diuretik, antihiperglikemik, laksatif, dan antioksidan (Ibrahim, dkk., 2017).

Kadar fenolik total dan kadar flavonoid total dapat digunakan untuk mengetahui aktivitas antioksidan. Hal ini karena terdapat hubungan yang linier antara kadar fenolik total dengan aktivitas antioksidan (Aryal, dkk., 2019). Selain itu, penelitian yang sudah dilakukan oleh Johari dan Khong (2019) menyatakan bahwa semakin tinggi kadar fenolik total, maka semakin tinggi pula aktivitas antioksidannya. Penelitian mengenai potensi antioksidan kacang panjang telah banyak dilakukan. Beberapa penelitian memaparkan bahwa biji kacang panjang memiliki aktivitas antioksidan yang baik (Sombie, dkk., 2018). Penelitian pada daun kacang panjang juga memperoleh aktivitas antioksidan yang baik (Rizky, 2018). Penelitian daging buah (pod) kacang panjang masih jarang dilakukan. Machado, dkk. (2016) menjelaskan bahwa ekstrak metanol daging buah kacang panjang memiliki aktivitas antioksidan. Selain itu, ekstrak aseton, kloroform dan etil asetat daging buah kacang panjang juga memiliki aktivitas antioksidan (Nehra, dkk., 2018). Penggunaan pelarut-pelarut tersebut tidak diizinkan oleh BPOM dalam pengolahan obat. Menurut Badan Pengawas Obat dan Makanan (2010), penggunaan pelarut yang diizinkan dalam pengolahan obat adalah etanol dan air.

Penggunaan pelarut merupakan salah satu parameter yang penting dalam mendapatkan senyawa tertentu dalam proses ekstrasi. Hal tersebut penting karena senyawa yang akan diambil akan larut dalam pelarut pengekstraksi. Kemampuan senyawa untuk larut dalam pelarut ini bergantung pada kepolaran pelarut dimana senyawa polar akan larut pada pelarut polar dan senyawa non polar akan larut dalam senyawa non polar (Anggitha, 2012). Pada penelitian ini digunakan etanol dan air sebagai pelarut ekstraksi karena merupakan pelarut yang mudah ditemukan, universal dan murah (Noviyanti, 2016). Kedua pelarut ini dapat menarik senyawa-senyawa polar seperti senyawa fenolik dan flavonoid (Subianto, dkk., 2013).

Kadar fenolik total dapat diketahui dengan metode spektrofotometri UV-Visible. Metode spektrofotometri UV-Visible digunakan untuk menganalisis golongan senyawa tertentu. Metode ini merupakan metode yang murah, mudah dan dapat diterima dibandingkan dengan metode kromatografi (Csepregi, dkk., 2013). Penentuan kadar fenolik total menggunakan metode spektrofotometri UVVisible dilakukan dengan reagen Folin-Ciocalteu.
Kompleks berwarna yang dihasilkan oleh reaksi antara reagen dengan senyawa fenolik atau flavonoid akan diukur absorbansinya menggunakan spektrofotometri $U V$-Visible sehingga diperoleh kadar fenolik total atau kadar flavonoid totalnya (Dani, dkk., 2010).

Berdasarkan hal tersebut, untuk mempertimbangkan kemungkinan pengaplikasian daging buah kacang panjang (Vigna unguiculata) sebagai bahan baku antioksidan alami, maka diperlukan data tentang potensi antioksidan melalui parameter kadar fenolik total dalam ekstrak etanol dan airnya.

\section{Metode}

Bahan

Pelarut etanol 96\% (Merck), $\mathrm{HCl}$ pekat (Merck), reagen Folin-Ciocalteu (Merck), serbuk $\mathrm{Na}_{2} \mathrm{CO}_{3}$ (Merck), serbuk $\mathrm{AlCl}_{3}$ (Merck), water, aqua bides (WaterOne). Standar asam galat dan kuersetin p.a diperoleh dari Sigma-Aldrich. Larutan $\mathrm{FeCl}_{3}$ dan serbuk Mg.

Sampel buah kacang panjang dari Pringgasela, Lombok Timur, Nusa Tenggara Barat. Sampel tersebut diidentifikasi dengan nama ilmiah Vigna unguiculata subsp. Sesquipedalis (L) Verdc.

\section{Alat \\ Spektrofotometer UV-Visible (double beam spectrophotometer)}

\section{Pengambilan sampel}

Buah kacang panjang diambil dari daerah Pringgasela, Lombok Timur, Nusa Tenggara Barat dengan karakteristik buah telah matang, berwarna hijau, berukuran $10-80 \mathrm{~cm}$, dan usia buah sekitar 33,5 bulan. Buah yang telah diperoleh dibuka untuk dipisahkan antara daging buah dan bijinya. Daging buah yang terkumpul dimaserasi.

\section{Preparasi sampel}

Sebanyak $12 \mathrm{~kg}$ daging buah kacang panjang yang terkumpul dikeringkan di bawah sinar matahari menggunakan kain hitam yang dilakukan selama 3 hari. Sampel daging buah kacang panjang yang telah kering dihaluskan dengan cara $d r y$ blender dan serbuk simplisia daging buah kacang panjang dimaserasi.

\section{Ekstraksi sampel}

Proses maserasi pada penelitian ini mengacu pada prosedur yang dilakukan oleh Abiat, dkk (20I4) dengan sedikit modifikasi. Maserasi dilakukan selama 24 jam dengan menggunakan pelarut etanol 96\%. Perbandingan serbuk simplisia dan pelarut 
yang digunakan adalah I:IO. Selama maserasi berlangsung, sampel diaduk setiap I jam pada 6 jam pertama. Setelah 24 jam, dilakukan filtrasi untuk memperoleh maserat dan diulangi proses maserasi sebanyak dua kali. Selanjutnya, maserat dikumpulkan dari setiap proses maserasi dalam satu wadah dan ekstrak diuapkan dengan penangas air sederhana pada suhu $\leq 50^{\circ} \mathrm{C}$.

\section{Skrining Fitokimia}

Fenolik

Skrining senyawa fenolik dilakukan dengan melarutkan 0,I gram ekstrak etanol kacang panjang dengan $10 \mathrm{~mL}$ akuades dan disaring. Hasil filtrat kemudian ditambahkan $\mathrm{FeCl}_{3} \mathrm{I} \%$ sebanyak 3 tetes. Hasil positif ditandai dengan terbentuknya warna hijau biru kehitaman (Alfian dan Susanti, 2012). Prosedur ini dilakukan juga pada ekstrak air kacang panjang.

\section{Penetapan kadar fenolik total}

Pembuatan larutan induk asam galat (0,05\%) Sebanyak $50 \mathrm{mg}$ asam galat dilarutkan dengan 0,5 $\mathrm{mL}$ etanol p.a dan diencerkan dengan akuades sampai $100 \mathrm{~mL}$ (Andriani dan Murtisiwi, 2018).

\section{Penentuan Operating Time (OT)}

Penentuan operating time (OT) dilakukan dengan menambahkan I,5 mL Folin Ciocalteu (I:I0) pada $300 \mu \mathrm{L}$ larutan asam galat konsentrasi 30 ppm. Selanjutnya, larutan digojog dan didiamkan selama 3 menit. Setelah itu, ditambahkan I,2 mL larutan $\mathrm{Na}_{2} \mathrm{CO}_{3} 7,5 \%$, lalu larutan digojog hingga homogen. Absorbansi larutan diukur dalam rentang waktu 0-60 menit pada panjang gelombang $765 \mathrm{~nm}$ (Andriani dan Murtisiwi, 2018).

Penentuan Panjang Gelombang Maksimum

Penentuan panjang gelombang maksimum dilakukan menggunakan $300 \mu \mathrm{L}$ larutan asam galat konsentrasi 30 ppm. Ditambahkan I,5 mL Folin Ciocalteu (I:IO) lalu larutan digojog dan didiamkan selama 3 menit. Setelah itu, ditambahkan I,2 mL larutan $\mathrm{Na}_{2} \mathrm{CO}_{3} 7,5 \%$, lalu larutan digojog hingga homogen dan larutan didiamkan pada suhu kamar pada operating time (OT) (Andriani dan Murtisiwi, 2018). Absorbansi larutan diukur pada panjang gelombang 400 - 800 nm (Hapsari, dkk., 2018).

Pengukuran Larutan Standar Asam Galat Pengukuran larutan standar asam galat dilakukan dengan membuat seri konsentrasi I0, 20, 30, 40 dan 50 ppm. Sebanyak $300 \mu \mathrm{L}$ masing-masing larutan diambil dan ditambahkan I,5 mL Folin Ciocalteu (I:IO), larutan digojog dan didiamkan selama 3 menit. Ditambahkan larutan $\mathrm{Na}_{2} \mathrm{CO}_{3}$ sebanyak I,2 $\mathrm{mL}$ lalu larutan digojog hingga homogen. Kemudian larutan didiamkan selama operating time (OT) pada suhu ruangan. Absorbansi larutan diukur pada panjang gelombang maksimum asam galat dan dibuat kurva kalibrasi asam galat (Andriani dan Murtisiwi, 2018).

Penentuan Kadar Fenolik Total Ekstrak Etanol dan Air Daging Buah Kacang Panjang (Vigna unguiculata)

Penentuan kadar fenolik total ekstrak etanol dan air daging buah kacang panjang dilakukan dengan menimbang $10 \mathrm{mg}$ masing-masing ekstrak dan ekstrak dilarutkan dengan $10 \mathrm{~mL}$ akuades lalu dihomogenkan. Sebanyak $300 \mu \mathrm{L}$ dari larutan tersebut diambil dan ditambahkan I,5 mL FolinCiocalteu, larutan dikocok dan dibiarkan selama 3 menit. Larutan ditambahkan $\mathrm{Na}_{2} \mathrm{CO}_{3}$ sebanyak I,2 mL, larutan dikocok hingga homogen dan didiamkan pada operating time (OT). Absorbansi larutan diukur pada panjang gelombang maksimum dalam 3 kali pengulangan (Andriani dan Murtisiwi, 2018). Kadar fenolik total dalam ekstrak etanol dan ekstrak air kacang panjang ditentukan menggunakan rumus berikut (Samin, dkk., 20I4):

Keterangan:

$$
\mathrm{TPC}=\frac{\mathrm{C} \cdot \mathrm{V} \cdot \mathrm{fp}}{\mathrm{g}}
$$

$\mathrm{TPC}=$ Total Phenolic Content

$\mathrm{C}=$ konsentrasifenolik (nilai $\mathrm{x}$ )

$\mathrm{V}=$ volume ekstrak yang digunakan $(\mathrm{mL})$

$\mathrm{Fp}=$ factor pengenceran

$\mathrm{g} \quad=$ berat sampel yang digunakan (gram)

\section{Hasil dan Pembahasan}

Pengambilan sampel

Sebanyak $18 \mathrm{~kg}$ sampel buah kacang panjang diambil dari daerah Pringgasela, Lombok Timur, Nusa Tenggara Barat. Pengambilan sampel dilakukan pada satu tempat untuk menghindari perbedaan varietas tanaman serta perbedaan kandungan metabolit sekunder di dalam tanaman. Sampel buah kacang panjang diambil pada sore hari dengan ciri-ciri tanaman yang masih segar, polongnya cukup tua, biji menonjol, dan warna kulit luar hijau kekuningan (Rukmana, I995). Sampel buah kacang panjang juga diambil ketika usia tanaman mencapa 33,5 bulan. 


\section{Persiapan sampel}

Sampel buah kacang panjang yang telah dikumpulkan kemudian dipisahkan antara biji dan daging buahnya. Daging buah kacang panjang yang diperoleh kemudian dibuat menjadi simplisia dengan tahapan sebagai berikut: sortasi basah, pencucian, perajangan, pengeringan, sortasi kering, penghalusan, dan penyimpanan (Depkes RI, I985). Melalui proses pembuatan simplisia diperoleh 439,4 gram serbuk simplisia daging buah kacang panjang.

\section{Ekstraksi sampel}

Ekstraksi simplisia daging buah kacang panjang yang telah diperoleh dilakukan dengan metode maserasi. Metode maserasi merupakan metode yang aman digunakan untuk senyawa termolabil seperti senyawa fenolik dan flavonoid (Susanty dan Bachmid, 2016). Maserasi simplisia daging buah kacang panjang dilakukan menggunakan dua pelarut yang berbeda, yaitu etanol $96 \%$ dan pelarut air. Etanol 96\% merupakan pelarut yang memiliki keefektifan lebih tinggi dalam menyari metabolit sekunder, sulit untuk ditumbuhi jamur dan bakteri, tidak beracun, memiliki penyerapan yang baik dan proses pemekatan yang diperlukan tidak memakan waktu (Sa'adah dan Nurhasnawati, 2015). Pelarut air merupakan pelarut polar yang dapat menyari sampel dalam tingkat kepolaran yang berbeda (Lumempouwa, dkk., 2012). Penggunaan pelarut etanol $96 \%$ dan pelarut air juga menguntungkan dari segi kesehatan sehingga menjadi pelarut yang aman untuk pengolahan obat (BPOM, 20I0). Setelah dilakukan maserasi, ekstrak etanol cair dan ekstrak air cair yang diperoleh kemudian dikentalkan dengan penangas air sederhana dengan suhu $\leq 50^{\circ} \mathrm{C}$. Data hasil rendemen ekstrak yang diperoleh dari masingmasing pelarut dapat dilihat pada tabel I.

Tabel I. Jumlah dan Rendemen Ekstrak

\begin{tabular}{cccc}
\hline $\begin{array}{c}\text { Jenis } \\
\text { Ekstrak }\end{array}$ & $\begin{array}{c}\text { Berat } \\
\text { Serbuk } \\
\text { Simplisia } \\
(\mathrm{g})\end{array}$ & $\begin{array}{c}\text { Berat } \\
\text { Ekstrak } \\
\text { Kental } \\
(\mathrm{g})\end{array}$ & $\begin{array}{c}\text { Rendemen } \\
\text { Ekstrak } \\
(\%)\end{array}$ \\
\hline $\begin{array}{c}\text { Ekstrak } \\
\text { Etanol }\end{array}$ & 100 & 7.12 & $7.12 \%$ \\
\hline $\begin{array}{c}\text { Ekstrak } \\
\text { Air }\end{array}$ & 100 & 15.345 & $15.345 \%$ \\
\hline
\end{tabular}

\section{Skrining fitokimia}

Skrining fitokimia dilakukan untuk mengetahui golongan senyawa yang terdapat dalam suatu tanaman secara kualitatif (Supomo, dkk., 2019). Skrining fitokimia yang dilakukan untuk mengetahui keberadaan senyawa fenolik dalam ekstrak etanol dan ekstrak air daging buah kacang panjang. Hasil skrining fitokimia yang menunjukkan bahwa ekstrak etanol buah kacang panjang positif mengandung senyawa fenolik dan flavonoid dapat dilihat pada gambar I.

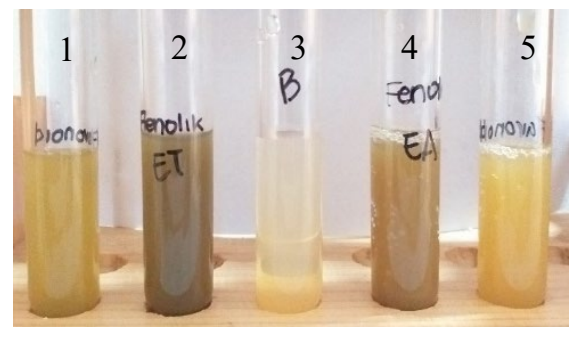

Gambar I. Hasil skrining fitokimia senyawa fenolik Keterangan

$\mathrm{I}=$ larutan ekstrak etanol dengan pereaksi $\mathrm{FeCl}_{3}$

$2=$ larutan ekstrak etanol tanpa pereaksi $\mathrm{FeCl}_{3}$

3 = larutan blanko

$4=$ larutan ekstrak air dengan pereaksi $\mathrm{FeCl}_{3}$

$5=$ larutan ekstrak air tanpa pereaksi $\mathrm{FeCl}_{3}$

Senyawa fenolik dikenal dengan kemampuannya sebagai antioksidan. Oleh karena itu, tanaman seperti tanaman polong yang mengandung senyawa fenolik berpotensi sebagai antioksidan. Tanaman polong yang mengandung senyawa fenolik selain kacang panjang adalah tanaman buncis (Utomo, dkk., 2018)

\section{Penetapan kadar fenolik total}

Penetapan kadar fenolik total dilakukan menggunakan metode Folin-Ciocalteu. Prinsip dari metode ini adalah reduksi fosfomolibdatfosfotungstat oleh inti aromatis senyawa fenolik sehingga terbentuk kompleks molibdenum tungsten yang berwarna biru (Senet, dkk., 2018). Reaksi antara reagen Folin-Ciocalteu dan senyawa fenolik hanya dapat terjadi pada suana basa, sehingga diperlukan penambahan natrium karbonat untuk membuat lingkungannya menjadi basa. Suasana basa ini dapat mendisosiasi proton pada senyawa fenolik menjadi ion fenolat (Ukieyanna, 2012).

Kurva baku asam galat dibuat dengan seri konsentrasi 10, 20, 30, 40, dan 50 ppm. Asam galat dipilih karena merupakan salah satu senyawa fenolik dengan struktur sederhana, memiliki sifat yang stabil, dan tersedia dalam keadaan murni (Senet, dkk., 2018). Melalui kurva standar asam galat tersebut akan diperoleh persamaan regresi linier yang kemudian digunakan untuk menentukan kadar fenolik total ekstrak etanol dan ekstrak air daging buah kacang panjang. Pengukuran absorbansi asam galat dilakukan menggunakan panjang gelombang maksimum $760 \mathrm{~nm}$ dengan operating time selama 45 menit. Absorbansi standar asam galat dapat dilihat pada tabel 2. Kurva kalibrasi asam galat yang diperoleh dapat dilihat pada gambar 2 . 
Tabel 2. Data Absorbansi Asam Galat

\begin{tabular}{cc}
\hline Konsentrasi (ppm) & Absorbansi \\
\hline 10 & 0.3307 \\
\hline 20 & 0.4654 \\
\hline 30 & 0.5992 \\
\hline 40 & 0.7098 \\
\hline 50 & 0.8449 \\
\hline
\end{tabular}

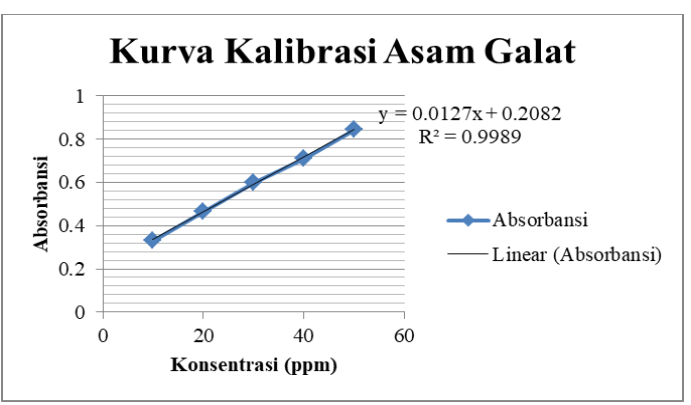

Gambar 2. Kurva kalibrasi asam galat

Dari pengukuran kurva kalibrasi asam galat, diperoleh persamaan regresi linier $y=0.0127 x+$ 0.2082 dengan nilai $R^{2}=0.9989$. Persamaan regresi linier ini kemudian digunakan untuk menghitung kadar fenolik total pada sampel ekstrak. Penetapan kadar fenolik sampel ekstrak dilakukan dengan mengukur absorbansi sampel ekstrak dengan spektrofotometer UV-Visible. Larutan sampel ekstrak etanol dan ekstrak air daging buah kacang panjang dibuat dengan konsentrasi 1000 ppm. Hasil kadar fenolik total ekstrak etanol dan eksttrak air daging buah kacang panjang dapat dilihat pada tabel 3.

Berdasarkan data pada tabel 3, dapat dilihat bahwa kadar fenolik total ekstrak dengan pelarut air lebih banyak dibandingkan dengan ekstrak dengan pelarut etanol. Hal ini dapat disebabkan oleh kepolaran dari pelarut air (konstanta dielektrik $=$ 80,37) lebih besar dibandingkan dengan etanol (konstanta dielektrik $=24,30$ ) sehingga dapat menarik senyawa fenolik dari ekstrak daging buah kacang panjang secara lebih banyak. Kecocokan antara kepolaran pelarut dan senyawa yang diambil juga mengambil peranan penting dalam hal ini. Senyawa fenolik yang terbagi menjadi beberapa jenis dengan tingkat kepolaran yang berbeda akan memengaruhi kelarutannya dalam suatu pelarut. $\mathrm{Hal}$ ini juga didukung oleh Komit, dkk. (2016) yang menyatakan bahwa suatu senyawa akan larut pada pelarut dengan kepolaran yang sama.

Kehadiran senyawa fenolik yang tinggi di dalam ekstrak menandakan bahwa ekstrak daging buah kacang panjang memiliki potensi antioksidan. Hal ini didukung oleh penelitian Aryal, dkk (2019) yang memaparkan bahwa terdapat hubungan yang linier antara kadar fenolik total dan kadar flavonoid total dengan aktivitas antioksidan. Selain itu, penelitian yang sudah dilakukan oleh Johari dan Khong (2019) menyatakan bahwa semakin tinggi kadar fenolik total, maka semakin tinggi pula aktivitas antioksidannya

Tabel 3. Hasil Penetapan Kadar Fenolik Total Ekstrak Etanol dan Ekstrak Air Daging Buah Kacang Panjang

\begin{tabular}{|c|c|c|c|c|c|}
\hline Sampel & Replikasi & $\begin{array}{l}\text { Konsentrasi } \\
\text { (ppm) }\end{array}$ & Absorbansi & $\begin{array}{l}\text { Kadar Fenolik Total } \\
\text { (mg GAE/g) }\end{array}$ & $\begin{array}{l}\text { Rerata Kadar } \\
\text { Fenolik Total } \\
\text { (mg GAE/g) }\end{array}$ \\
\hline Ekstra & $\mathrm{I}$ & \multirow{3}{*}{1000} & 0,3588 & 35,5748 & \multirow{3}{*}{$\begin{array}{c}40,4173 \pm \\
4,2303\end{array}$} \\
\hline k & 2 & & 0,3919 & 43,3937 & \\
\hline Etanol & 3 & & 0,3872 & 42,2835 & \\
\hline \multirow{3}{*}{$\begin{array}{l}\text { Ekstra } \\
\text { k Air }\end{array}$} & $\mathrm{I}$ & \multirow{3}{*}{1000} & 0,4773 & 63,5669 & \multirow{3}{*}{$\begin{array}{l}60,6062 \pm \\
2,8533\end{array}$} \\
\hline & 2 & & 0,4532 & 57,8740 & \\
\hline & 3 & & 0,4638 & 60,3779 & \\
\hline
\end{tabular}

\section{Simpulan dan Saran}

Kadar fenolik total yang dapat diperoleh dari ekstrak etanol kacang panjang sebesar 40,4173 \pm $4.2303 \mathrm{mg} \mathrm{GAE} / \mathrm{g}$ dan kadar fenolik total yang dapat diperoleh dari ekstrak air kacang panjang adalah $60.6062 \pm 2,8533 \mathrm{mg}$ GAE/g. Ekstrak etanol dan ekstrak air dari daging buah kacang panjang berpotensi sebagai antioksidan dilihat dari parameter kadar fenolik total. Berdasarkan penelitian, diperoleh bahwa kadar fenolik total ekstrak air lebih tinggi dibandingkan ekstrak etanol daging buah kacang panjang.

\section{Daftar Pustaka}

Abiat, A., Jamaludin, M., Khalijah, A., Jamil, A.S. dan Aditya, A., (20I4). Evaluation of antidiabetic and antioxidant properties of Brucea javanica seed. The Scientific World Journal. 20I4, I-8.

Alfian, R. Dan Susanti, H. (2012). Penetapan kadar fenolik total ekstrak metanol kelopak bunga rosella merah (Hibiscus sabdariffa Linn) dengan variasi tempat tumbuh secara spektrofotometri. Pharmaciana. 2(I), 7380. 
Andriani, D. dan Murtisiwi, L., (2018). Penetapan kadar fenolik total ekstrak etanol bunga telang (clitoria ternatea 1.) dengan spektrofotometri uv-vis. Cendekia Journal of Pharmacy. 2(I), 32-8.

Anggitha, I. (2012). Performa Flokulasi Bioflokulan DYT Pada Beragam Keasaman dan Kekuatan Ion Terhadap Turbiditas Larutan Kaolin. Jakarta: Universitas Pendidikan Indonesia.

Aryal, S., Baniya, M.K., Danekhu, K., Kunwar, P., Gurung, R., dan Koirala, N. (2019). Total phenolic content, flavonoid content and antioxidant potential of wild vegetables from western nepal. Plants. 8(96), I-I2.

Badan Pengawas Obat dan Makanan. (2010). Monografi Ekstrak Tumbuhan Obat. Jakarta: Badan Pengawas Obat dan Makanan.

Csepregi, K., Kocsis, M., dan Hideg, E., (2013). On the spectrophotometric determination of total phenolic and flavonoid contents. Acta Biologica Hungarica. 64(4), 500-9.

Dani, C., Oliboni, L.S., Agostini, F., Funchal, C., Serafani, L., Henriques, J.A., dan Salvador, M., (20I0). Phenolic content of grapevine leaves (Vitis labrusa var. Bordo) and its neuroprotective effect againts peroxide damage. Toxicology in Vitro.24(2010), I48-53.

Depkes RI. 1985. Cara Pembuatan Simplisia. Jakarta: Departemen Kesehatan Republik Indonesia.

Hapsari, A.M., Masfria, dan Dalimunthe, A., (2018). Pengujian kandungan total fenol ekstrak etanol tempuyung (Shoncus arvensis L.). Tropical Medicine Conference Sciences. 0I(2018), 284-90.

Hermawan, A., Rochdiani, D., dan Hardiyanto T., (2015). Analisis usahatani kacang panjang (Vigna sinensis L.) varietas parade. Jurnal Ilmiah Mahasiswa AGROINFO GALUH. I(2), 77-82.

Ibrahim, S.V.K., Satish, S., Kumar, A., dan Hegde, K., (2017). Pharmacological activities of Vigna unguiculata (L) Walp: a review. International Journal of Pharma and Chemical Research. 3(I), 44-9.

Johari, M.A. dan Khong, H.Y., (2019). Total phenolic content and antioxidant and antibacterial activities ofPereskia bleo. Hindawi Advance in Pharmacological Sciences. 2019, I-4.

Komit, N. Widarta, I.W.R., dan Nocianitri, K.A. (2016). Pengaruh jenis pelarut dan waktu maserasi terhadap kandungan senyawa flavonoid dan aktivitas antioksidan ekstrak daun alpukat (Persea americana Mill). Jurnal Ilmu dan Teknologi Pangan. 5(2), I30-4I.

Lumempouwa, L.I., Suryantoa, E. dan Paendonga, J.J.E. (20I2). Aktivitas anti UV-B ekstrak fenolik dari tongkol jagung (Zea mays L.). Jurnal MIPA UNSRAT Online. I(I), I-4.

Machado, N., Dominguez-Perles, R., Ramos, A., Rosa, E.A.S., dan Barros, A.I.R.N.A., (2017). Spectrophotometric versus nir-mir assessments of cowpea pods for dicriminating the impact of freezing. J.Sci.Food.Agric. 2017, I-IO.

Nehra, S., Singh, S., dan Rani, S., (2018). Assessment of pod coats for the study of antioxidant prospective in cowpea, mungbean and moth bean. International Journal of Current Microbiology and Applied Sciences. 7(3), 3476-83.

Noviyanti., (2016). Pengaruh kepolaran pelarut terhadap aktivitas antioksidan ekstrak etanol daun jambu brazil batu (Psidium guineense L.) dengan metode DPPH. Jurnal Farmako Bahari. 7(I), 29-35.

Rahayu, E., Haryanto, E., dan Suhartini., (2003). Seri Agribisnis: Budidaya Kacang Panjang. Jakarta: Penebar Swadaya.

Rizky, D., W., (2018). Uji aktivitas antibakteri dan antioksidan ekstrak metanol daun kacang panjang (Vigna ungiculata (L.) Walp). Skripsi. Program Studi SI Kimia, Universitas Sumatera Utara.Medan.

Sa'adah, H. dan Nurhasnawati, H. (2015). Perbandingan pelarut etanol dan air pada pembuatan ekstrak umbi bawang tiwai (Eleutherine americana Merr) menggunakan metode maserasi. Jurnal Ilmiah Manuntung. I(2), I49-53.

Samin, A.A., Bialangi, N., dan Salimi, Y.K., (2014). Penentuan kandungan fenolik total dan aktivitas antioksidan dari rambut jagung (Zea mays L.) yang tumbuh di daerah gorontalo. Jurnal SAINTEKS. 7(3): 21326.

Sombie, P.A.E.D., Campaore, M., Coulibaly, A.Y., Ouedraogo, J.T., Tingnegne, J.D.L.S., dan Kiendrebeogo, M., (2018). Antioxidant and phytochemical studies of 3 I cowpeas (Vigna ungiculata (L. Walp.)) genotypes from burkina faso. Foods. 7(I43), I-9.

Senet, M.R.M., Raharja, I.G.M.A.P., Darma, I.K.T., Prastakarini, K.T., Dewi, N.M.A., dan Parwata, I.M.O.A. (2018). Penentuan 
kandungan total flavonoid dan total fenol dari akar kersen (Mutingia calabura) serta aktivitasnya sebagai antioksidan. Jurnal Kimia. I2(I), I3-8.

Subianto, C., Srianta, I., dan Kusumawati, N., (2013). Pengaruh proporsi air dan etanol sebagai pelarut terhadap aktivitas antioksidan angkak biji durian dengan metode phosphomolybdenum dan DPPH. Jurnal Teknologi Pangan dan Gizi. I2(2), 75-80.

Susanty, S., dan Bachmid, F., (2016). Perbandingan metode ektraksi maserasi dan refluks terhadap kadar fenolik dari ekstrak tongkol jagung (Zea mays L.). Konversi. 5(2), 8793.

Supomo, Warnida, H., dan Sahid, B.M. (2019). Perbandingan metode ekstraksi ekstrak umbi bawang rambut (Allium chinse G.Don.) menggunakan pelarut etanol 70\% terhadap rendemen dan skrining fitokimia.Jurnal Riset Kefarmasian Indonesia. I(I), 30-40.

Ukieyanna, E. (20I2). Aktivitas antioksidan, kadar fenolik, dan flavonoid total tumbuhan suruhan (Peperomia pellucida L. Kunth). Skripsi. Fakultas Matematika dan Ilmu Pengetahuan Alam.Institut Pertanian Bogor.

Utomo, V.Y., Andayani, Y. dan Gunawan, E.R. (20I8). Potensi antioksidan hasil fraksinasi ekstrak etanol Phaseolus vulgaris L. Jurnal Penelitian Pendidikan IPA (JPPIPA), 4(I), I-4. 